\title{
Incentivando a Aprendizagem de Arquitetura de Computadores em Cursos de Computação Através de um Simulador do Microprocessador Z-80 com Kahoot!
}

\author{
Rodrigo Alves Costa' ${ }^{1}$, André Luiz H. Bernardo' ${ }^{1}$ Ingrid Morgane M. de Lucena' \\ Ciências Exatas e Sociais Aplicadas - Universidade Estadual da Paraíba (UEPB) \\ Patos - PB - Brasil \\ rodrigo@ccea.uepb.edu.br, \{andrehenriquesb, ingridmorgane\}@gmail.com
}

\begin{abstract}
This paper describes the application of a Z-80 microprocessor simulator in the discipline of Computer Architecture in the Computer Science course of the State University of Paraiba, under the hypothesis that it would provide better understanding on the subject of Processors to the students. To assess the improvement in learning, two evaluations were applied, one prior to the explanation and execution of routines in the simulator, and another one afterwards. These were applied using the Kahoot! learning environment, based on gamification, which served as a motivator for the students during the evaluation process. There was an increase of $8.3 \%$ in the average number of hits and high satisfaction rates with the overall experience.
\end{abstract}

Resumo. Este trabalho trata-se da aplicação de um simulador do microprocessador Z-80 na disciplina de Arquitetura de Computadores no curso de Computação da Universidade Estadual da Paraíba, sob a hipótese que a mesma proporcionaria uma maior compreensão sobre o assunto de processadores aos alunos. Para aferir a melhoria na aprendizagem, foram aplicadas duas avaliações de mesmo nível, uma antes da explicação e execução de rotinas no simulador, e outra depois. Elas foram aplicadas utilizando o ambiente qualificador de aprendizagem Kahoot!, baseado em gamificação, motivador para os estudantes durante o processo avaliativo. Verificou-se um aumento de 8,3\% na média de acertos e altos índices de satisfação com a experiência.

\section{Introdução}

De acordo com a ementa do curso de Computação do Campus VII da Universidade Estadual da Paraíba [Costa et al. 2016], o componente curricular de Arquitetura de Computadores está associado ao ensino de toda a estrutura básica de hardware de computadores. Um dos assuntos mais importantes nessa disciplina é o de Processadores. Devido à complexidade no processamento de instruções e na construção do mesmo, muitas vezes docentes se limitam a teorizar sobre arquiteturas e funcionalidades básicas.

Este trabalho surge da hipótese que, através da explanação e execução de rotinas de simuladores de Processadores em turmas cujo conteúdo é abordado, a sua aprendizagem será otimizada. Para verificação dessa hipótese e, consequentemente, a manutenção de um grau satisfatório de envolvimento dos estudantes ao longo da experiência, decidiu-se utilizar uma ferramenta de gamificação, o Kahoot! [Dellos 2015]. 
VII Congresso Brasileiro de Informática na Educação (CBIE 2018)

Anais do XXIV Workshop de Informática na Escola (WIE 2018)

A gamificação é uma abordagem que pode auxiliar o problema da motivação no contexto educacional, através de elementos de jogos, proporcionando engajamento no processo de ensino-aprendizagem [da Rocha Seixas et al. 2016]. Nesse sentido, o Kahoot! é um ambiente que possibilita a realização de avaliações e questionários através de um sistema de pontuação em jogos pré-concebidos, criando um ambiente gamificado, no qual se busca acertar questões que são propostas como desafios [Dellos 2015].

Por sua vez, para Monteiro (2012), uma boa estratégia para o ensino de Processadores consiste em mostrar uma arquitetura simplificada de um processador, para servir como apoio aos fundamentos sobre seus componentes internos, funções e integração de procedimentos de instrução individual e em bloco, como um programa.

Em meados de 1973, foi concebido o Z-80, um processador de 8 bits que, devido à sua simplicidade e seu baixo custo, se tornou popular, sendo o mais vendido da história. Versões modernizadas (conservando o mesmo projeto básico, mas produzidos com técnicas modernas, trabalhando com frequências mais altas) são utilizados em eletrônicos até hoje, como calculadoras, MP3 Players e impressoras. Devido à sua simplicidade, além de possuir de baixo custo, também é de fácil implementação [Stallings 2010].

Com efeito, existem diversos processadores que poderiam ter versões simuladoras desenvolvidas, tais como: 8080a, 8088 e 4040 da Intel e o 64000 da Motorola [Stallings 2010]. No entanto, com a alta disponibilidade e interfaces simplificadas do Z-80, por ele apresentar uma arquitetura eficaz, por essa conter todos os componentes típicos de processadores e por ele ser muito usado como metodologia de ensino [Mudge e Buzzard 1983], o Z-80 tornou-se uma escolha natural para a aplicação como escolha metodológica da intervenção descrita neste artigo.

\section{Procedimentos Metodológicos}

De acordo com Gil (2011), o objetivo fundamental de um trabalho científico é descobrir respostas para problemas mediante o emprego de procedimentos. Aprofundar um conhecimento extenso e detalhado sobre um objeto, a fim de realizar um estudo profundo caracteriza um estudo de caso [Gil 2011]..

Neste sentido, Gil (2011), aponta que trabalhos descritivos propõem definições de características de populações definidas, como as que estudam características de um grupo. A saber, ao fim da atividade, foi aplicado um questionário de satisfação, no qual se utilizou a escala de "Questionário de Experiência com o Usuário" (QEU) [Falavigna 2015], buscando medir a atratividade em relação ao simulador do Z-80. De acordo com Triviños (1987), na pesquisa quantitativa descreve-se principalmente, do conceito da medida e comparação de dados de maneira elementar, discreta.

Este trabalho abordou uma turma do curso de Computação, grupo que caracteriza um estudo de caso. A avaliação da experiência com questionários determina o caráter descritivo do estudo, comparativo e quantitativo, levando em consideração os dados obtidos nas avaliações realizadas antes e depois da explanação do conteúdo. Assim, este trabalho trata-se de um estudo de caso descritivo com abordagem quantitativa discreta.

\subsection{Preparação para a Intervenção}

O primeiro passo do trabalho foi pesquisar e obter uma implementação satisfatória do microprocessador Z-80. Após pesquisa inicial, observou-se implementações com base 
VII Congresso Brasileiro de Informática na Educação (CBIE 2018)

Anais do XXIV Workshop de Informática na Escola (WIE 2018)

nas aplicações de Diab e Demashkieh (1991) e Mudge e Buzzard (1983). Como a segunda implementação estava pronta para aplicação e o código disponível para uso, enquanto a primeiro estava parcialmente em pseudo-código, sua implementação foi escolhida.

Uma parte significativa do código, para os propósitos da aplicação em sala de aula, precisou ser alterado. A principal modificação necessária foi adicionar instruções para mostrar a quantidade de ciclos por instrução da linguagem Assembly. As alterações podem ser encontradas nas linhas 47, 54 e 60 na Figura 1, que possui a nova versão do código, em linguagem Java.

Para realizar a apresentação e aplicação do simulador do microprocessador Z-80 em sala de aula, foi realizada uma revisão sobre o tema de microprocessadores e temas tais como unidade central de processamento, instrução, memória de instrução.

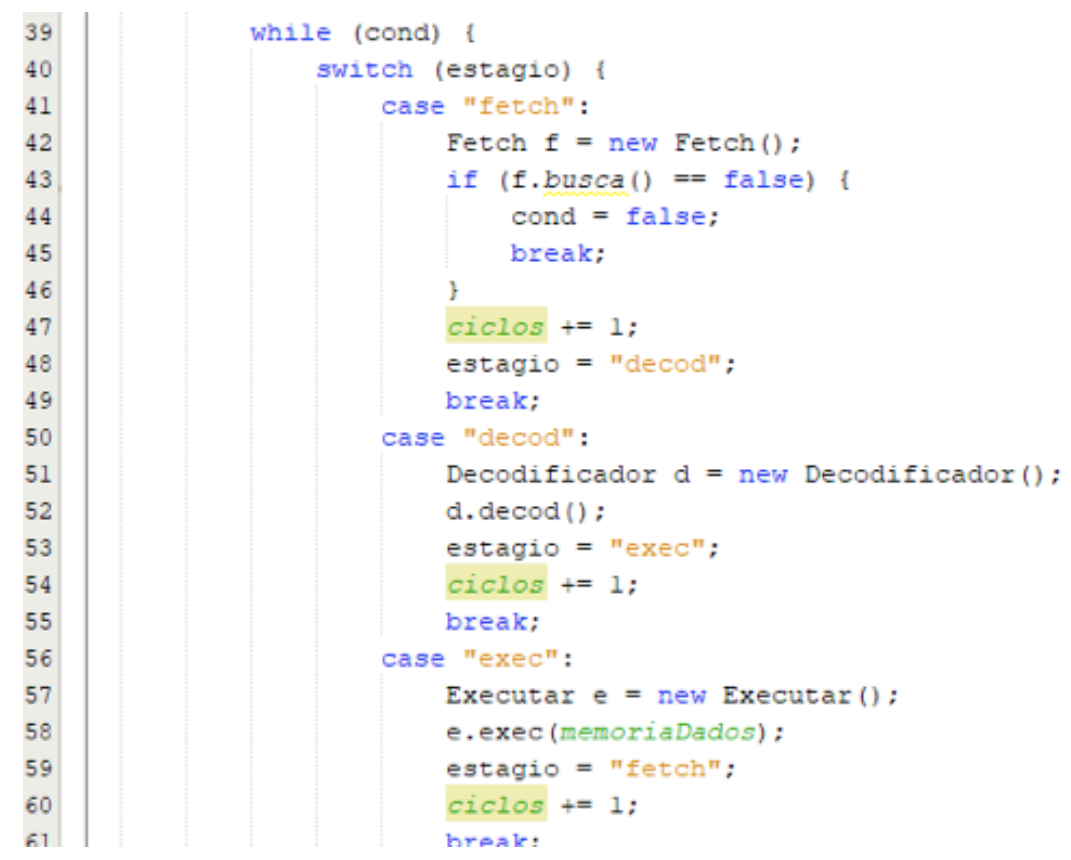

Figura 1: Código modificado do simulador do microprocessador Z-80

Com base em Cypriano (1984), Monteiro (2012) e Stallings (2010), adotados na ementa da disciplina, foram elaboradas 20 questões sobre processadores, das quais 10 foram aplicadas antes da apresentação do simulador e 10 depois. O método de avaliação foi o Kahoot! (ver Figura 2), de fácil identificação e organização dos dados gerados, e 16 alunos participaram.

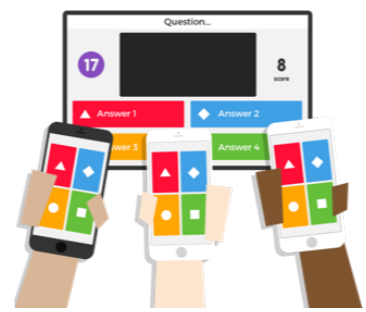

Figura 2: Possibilidades de interação com o Kahoot!

Como os alunos não estavam recebendo nenhuma pontuação extra na disciplina para participar da atividade, uma estratégia para envolvê-los foi utilizar a plataforma, que 
VII Congresso Brasileiro de Informática na Educação (CBIE 2018)

Anais do XXIV Workshop de Informática na Escola (WIE 2018)

acaba motivando através da estrutura baseada em jogos. Não se trata de um aplicativo: os estudantes não precisam de um Kahoot!, precisam apenas de qualquer dispositivo com navegador da Web [Dellos 2015].

Assim, último passo da intervenção foi a portabilidade das questões e a preparação do QEU, para medição de satisfação com a experiência, para o Kahoot!. O questionário conteve questões que buscavam entender se: i) os alunos gostaram da experiência, ii) já haviam tido alguma experiência com simuladores de hardware, iii) consideravam que a experiência tinha melhorado a compreensão do assunto visto em sala de aula, e iv) gostariam de outras experiências como essa em componentes curriculares similares, conforme recomendado por Falavigna (2015) para avaliações dessa natureza.

\section{Resultados}

Percebe-se que a atividade se demonstrou proveitosa. Pela escala QEU, pode-se medir que $87,5 \%$ dos alunos nunca haviam tido acesso a um simulador de hardware antes, mesmo na universidade. A experiência recebeu uma nota de 9,2 (escala de 0 a 10) como sendo "muito útil" para a formação acadêmica dos estudantes.

Por viabilizar aos alunos um método de avaliação que media o conhecimento sobre o assunto, a utilização do Kahoot como método de consideração mostrou-se satisfatório, pois não interferiu diretamente no resultado das avaliações e permitiu, da parte dos estudantes, um comprometimento significativo com a experiência.

A primeira avaliação foi realizada antes de qualquer explicação sobre o assunto ou o simulador, muito embora o conteúdo já houvesse sido ministrado pela professora. É importante ressaltar que as questões possuíam um nível de dificuldade progressivo em ambas as avaliações e abordavam assuntos semelhantes em cada questão, para possibilitar uma margem comparativa confiável. A diferença na quantidade de acertos por questão e a média total pode ser observada no Gráfico 1.

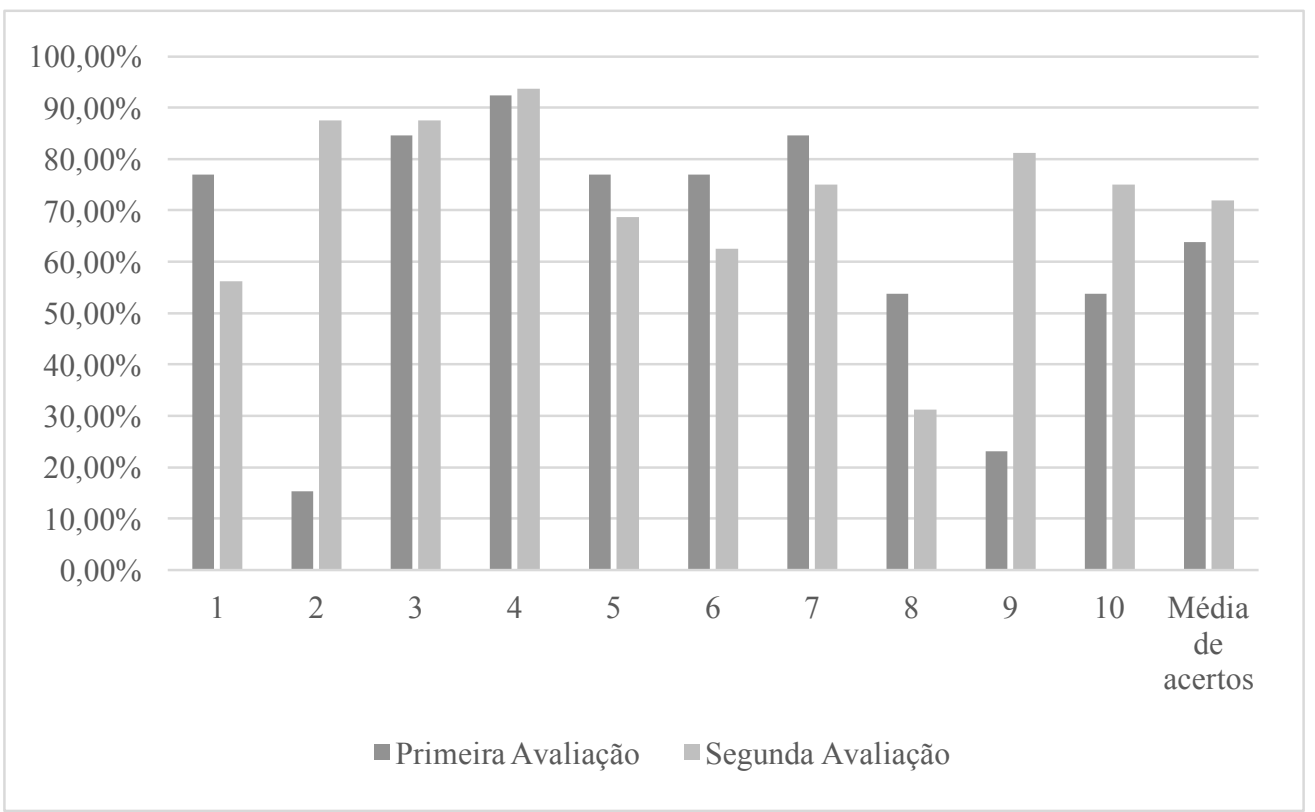

Gráfico 1: Diferença da quantidade acertos entre a primeira e a segunda avaliação por questão e na média total de acertos 
VII Congresso Brasileiro de Informática na Educação (CBIE 2018)

Anais do XXIV Workshop de Informática na Escola (WIE 2018)

Na primeira avaliação, houve uma média total de 64,9\% de acertos. Após a explanação do simulador e a execução de rotinas no mesmo, foi aplicada a segunda avaliação, que obteve uma média total de $75 \%$, um aumento significativo de $8,3 \%$.

\section{Considerações Finais}

Devido ao fato de possibilitar uma motivação com base em gamificação, o uso do Kahoot! foi adequado para a experiência, já que não houve nenhuma motivação adicional para os alunos participarem das atividades envolvidas na intervenção descrita neste trabalho. Conforme verificado pelo QEU, a alta taxa de satisfação de 9,2 demonstra a necessidade de trabalhar conteúdos práticos no contexto dessa disciplina e de outras do curso. Com efeito, foi perceptível que a aplicação do simulador do microprocessador Z80 e a revisão de conteúdos associada à mesma foi relevante para a aprendizagem, tendo promovido uma maior assimilação nos acadêmicos acerca do conteúdo que havia sido previamente abordado.

Como trabalhos futuros, parece ser positivo estender essa experiência para turmas maiores, ampliar o universo da pesquisa e vislumbrar a possibilidade de tornar a aplicação de simuladores como uma atividade fixa na disciplina. Planejar atividades semelhantes em outras disciplinas foi uma sugestão realizada ao corpo docente e núcleo docente estruturante do curso, dados os resultados obtidos deste trabalho.

\section{Referências}

Costa, R. A., et al. (2016), Projeto Pedagógico de Curso: Computação. Universidade Estadual da Paraíba.

Cypriano, L. B. (1983), Multiprocessador Z80 Hardware. 1. ed. São Paulo: Livros Érica Editora.

da Rocha Seixas, L., Gomes, A. S., and de Melo Filho, I. J. (2016). Effectiveness of gamification in the engagement of students. Computers in Human Behavior, 58:4863.

Dellos, R. (2015), "Kahoot! A digital game resource for learning”. In: International Journal of Instructional Technology and Distance Learning, 12(4), p. 49-52.

Diab, H B., Demashkieh, I., (1991), A Computer-Aided Teaching Package for Microprocessor Systems Education. 5 p.

Falavigna, V. D. (2015), "Experiência do Usuário: Análise e Aplicação de Métodos de Avaliação". Dissertação de Mestrado, Universidade de Caxias do Sul.

Gil, A. C. (2011), Métodos e técnicas de pesquisa social. 5 ed. São Paulo: Atlas.

Monteiro, R. (2012), Introdução à Organização de Computadores, 5. ed. Edição, LTC,

Mudge, T. N., Buzzard, G. D, (1983), “Teaching Assembly Language Programming with ZIP, a Z80 Assembly Language Interpreter Program”. Univ Illinois, New England.

Stallings, W. (2010), Arquitetura e Organização de Computadores. 8. ed. São Paulo: Pearson Pratice Hall.

Triviños, A. N. S. (1987), Introdução à pesquisa em ciências sociais: a pesquisa qualitativa em educação. São Paulo: Atlas. 